\title{
DIGITALIS IN HEART FAILURE WITH NORMAL RHYTHM
}

\author{
BY \\ C. J. GAVEY * and JOHN PARKINSON $\dagger$ \\ (From the Cardiac Department of the London Hospital)
}

In the first edition of his Diseases of the Heart, published in 1908, Mackenzie said : " the nodal rhythm is present in the majority of cases of severe heart failure and in a great many the immediate breakdown is directly attributable to the inception by the heart of this abnormal rhythm." In the third edition, in 1913, the term "auricular fibrillation" was substituted for that of " nodal rhythm," the researches of Lewis and others having established their identity. Mackenzie gave the proportion as " 60 or 70 per cent. of all cases of serious heart failure met with in practice." It is even now generally admitted that auricular fibrillation affects the majority. Lewis (1937) has said that at least 70 per cent. of all cases of failure with congestion display fibrillation.

To quote Mackenzie (1911) on digitalis : "Cases of auricular fibrillation are more readily and more markedly affected than cases with normal rhythm." Dissentient views began to be expressed perhaps first by Janeway (1913), and later especially by Christian (1919) whose paper was entitled "Digitalis therapy : satisfactory effects in cardiac cases with regular rhythm." In a further study (Christian, 1922) he affirmed that : "Digitalis is fully as effective in the treatment of chronic cardiac cases without auricular fibrillation as it in those with fibrillation." Luten (1924) reached the same conclusion. Yet most authors to-day admit that the beneficial effect is greater in auricular fibrillation, though they do not deny (and Mackenzie did not) that it is also effective in heart failure without fibrillation. Lewis's experience is that occasional cases presenting regular heart action respond favourably (Lewis, 1937).

We have spoken as if auricular fibrillation occurred indiscriminately in heart failure and as if the response to digitalis depended simply on the presence or absence of this arrhythmia. But it might be that fibrillation connoted a different group of cardiac lesions and thereby a different reaction to digitalis. It was with this idea in mind that Parkinson and Clark-Kennedy (1926) undertook an inquiry into heart failure with normal rhythm. It was established that there is an important relation between the pathological basis for a cardiac disease and failure and the presence or absence of fibrillation. In general, 
auricular fibrillation was the rule in rheumatic heart disease and goitre, while failure with normal rhythm was the rule in hypertension, coronary disease, and emphysema.

Apart from the factor of rhythm and the factor of a specific pathology conditioning rhythm, there is a third factor of the heart-rate during failure. A regular rhythm failure may occur with a normal or moderate ventricular rate, or a high rate. This has been much discussed (Mackenzie, 1911 ; Sutherland, 1919 ; Christian, 1922 ; Hay, Jones, and Ince, 1927 ; Marvin, 1927 ; and Luten, $1936 a, b)$. Apart from its pharmacological interest, the rate in failure with normal rhythm might indicate where digitalis acts beneficially, e.g. those with a high rate might respond and those with a normal rate might not respond.

The question we have placed foremost in this inquiry is how often and how far digitalis can help in a clinical sense patients who are suffering from heart failure without auricular fibrillation. It was hoped also to learn something from the kind of failure, the ætiology, the pathological basis, or the ventricular rate, which would aid in selecting the patient most suited for digitalis treatment. This clinical discrimination in the use of digitalis in heart failure with normal rhythm should soon be settled, because a mercurial diuretic will in future so often be employed alone or along with it that the separate effect of each should be established.

\section{METHOD OF INVESTIGATION}

Our observations were made chiefly on patients admitted to the beds of the Cardiac Department of the London Hospital over a period of eighteen months ending July 1938. Every patient considered to be suffering from congestive heart failure with normal rhythm was admitted for therapeutic observation. A combination of two or more of the following criteria was required : obvious dyspnœa, œdema, enlargement of the liver, congested lungs with or without hydrothorax, and venous distension in the neck. Left ventricular failure with paroxysmal dyspnœa and without systemic congestion was excluded from this inquiry. The degree of failure was assessed as slight or as moderate to severe. An electrocardiogram was taken. The chest was examined by X-rays and by teleradiograph when necessary. If a hydrothorax was present, teleradiograms were taken at intervals to register progress. The Wassermann reaction was tested except in a few of the rheumatic group. The blood urea was estimated and primary renal disease was excluded clinically and occasionally by necropsy.

For a period of at least a week no active treatment was ordered and the patient simply remained in bed. If digitalis had been given before admission, this control period was extended. A few patients were so ill on admission that strophanthin or salyrgan had to be given intravenously ; if so, an additional period without drugs was arranged. But if at about the fifth day of rest alone a patient was worse, it was felt unnecessary to withhold digitalis any longer for control purposes. A sedative (usually morphine) was given at night if required. Fluids were not often restricted and so the disturbing factor of another therapeutic measure was avoided. It proved that $40 \mathrm{oz}$. (1,137 c.c.) daily was 
seldom exceeded, but in a few where fluid was restricted to $30 \mathrm{oz}$. (852 c.c.) the restriction was equally applied during the rest and the digitalis period Frequent clinical notes were made in order to assess the rate and the extent of any improvement in the symptoms and signs of failure. During the control period we had to reject a number of cases because of pyrexia or other complications such as pulmonary infarction. Sometimes rest in bed alone was so beneficial that the residual failure was incompatible with adequate observations on digitalis action.

\section{The Digitalis Course}

Digitalis was administered in friable tablets containing one grain of the powdered leaf, pulvis digitalis folia, B.P., which is standardized biologically to contain 10 international units per gramme. This preparation is identical with that in the United States Pharmacopœia of 1936. The usual dose was 2 grains three times a day ( 6 grains or $0.4 \mathrm{~g}$. daily). In the early cases 1 grain three times a day was given for 14 days, but its effect was less easily demonstrated. Sometimes 3 grains three times a day were given and then usually in the more resistant cases or at a subsequent test. The normal period of digitalis administration was 7 days. It was found that 2 grains three times a day was a practicable dose and rarely led even to slight toxic effects, and then only towards the end of the test.

Certain criteria were considered for determining the result of rest in bed alone and of the digitalis course. Little attention was given to the patient's feelings expressed in response to the usual polite enquiries, for these are so much influenced by the patient's good will. Observed dyspnœa at rest or on slight movement was important, as were also the degree of distress and obvious discomfort including cough, insomnia, epigastric (hepatic) discomfort, and flatulence bound up with failure. The rate of the respiration was charted, but it seemed little related to the degree of dyspnœa as felt by the patient or observed by the physician. As Christian (1922) said : "Dyspnœa is poorly, sometimes not at all, depicted by the charted rate of respiration." Crepitations at the bases of the lungs were not of much value, as they often disappeared with the first few days of rest. Hydrothorax always figured in the rating, but its place and importance would scarcely have been realized had X-ray examination of the chest in failure not been practised. So objective a sign as œdema must always be an important index of progress. The size of the liver was almost as important. Diuresis and loss of weight were valuable criteria. The venous distension did not prove generally serviceable as a guide to the progress of improvement, and the same may be said of cyanosis.

Digitalis Effect or Digitalis Benefit.-The result of the digitalis course might be considered either as a pharmacological effect or as therapeutic benefit. Fall in heart-rate was not here regarded as an indication of therapeutic benefit, and this policy enabled us to observe the relation of slowing to benefit as assessed by our criteria of improvement, e.g. loss of œdema.

In most patients only one course of digitalis was studied ; but in a few cases of persistent failure two courses of digitalis were observed during the stay in 
hospital. When further observations were made during a subsequent admission, the patient was regarded as a new case.

Failure with Auricular Fibrillation.-Although this paper mainly concerns failure with normal rhythm, we have also studied in like manner thirty cases of failure with auricular fibrillation for comparison. The ventricular rate was counted at the apex daily throughout both the control period and the digitalis period.

Salyrgan.-In several cases salyrgan, 2 c.c., was given intravenously either immediately following the end of the digitalis course or else a few days later, so as to judge whether a diuresis was possible by means other than digitalis. Neither ammonium chloride nor ammonium nitrate was used as an adjuvant.

\section{Classification of Cases}

The choice of cases was made primarily on the presence of cardiac failure with normal rhythm, and without regard to the ætiology of the causal heart disease. Hypertensive, rheumatic, and syphilitic heart disease together formed the bulk of the cases (Group 1-4; Table I). Of the ten syphilitic cases, all had aortic incompetence. Group 5 included atheromatous aortic incompetence and coronary disease without hypertension or cardiac infarction. No typical example of heart failure from emphysema was found.

There were 22 observations on 18 patients with heart failure and normal rhythm who are classified among subsidiary groups, namely: congenital heart disease, acute rheumatic carditis with valvular disease, infective endocarditis, complete heart-block, and chronic nephritis. They were treated just the same, but they were patients in whom digitalis would not usually be employed or in whom its action would be less promising. Thyrotoxic heart disease was excluded.

\section{Previous ObServations}

The main question is how far digitalis can benefit patients with failure in normal rhythm ; and the further question is the comparable benefit in failure with auricular fibrillation. Though there are a large number of statements based only on personal experience and conviction, there are a limited number of detailed studies of these questions. The largest series are those of Christian (1922), Luten (1924), and Marvin (1927).

Christian contrasted 40 cases of normal rhythm with 57 cases of auricular fibrillation. Though without preliminary control periods, there is good evidence of successful treatment which was independent of rhythm. In both classes, his high percentage of successes is augmented by the inclusion of a reduced heart-rate as an indication of success. Possibly, too, the restricted fluid favoured his results.

Luten studied 20 cases of failure with normal rhythm. After control observation, he gave digitalis in massive doses (Eggleston method) and found that "digitalis affected most of the cases favourably." These results applied to failure from chronic myocarditis with or without hypertension or œdema. 
No cases with auricular fibrillation were used for comparison, but the conclusion was that " patients with myocardial insufficiency improve under proper digitalis administration in about the same proportion of cases as do patients with auricular fibrillation."

Marvin investigated 20 cases of advanced congestive failure with much œdema, paying particular attention to ætiology in relation to the digitalis response. Eggleston's method of administration was used after a control period of observation. Benefit from digitalis followed in 11 of the 20 cases ; none in the rheumatic group of $5 ; 3$ in the syphilitic group of 5 ; and 8 in the arteriosclerotic group of 10 ; but only two cases (both in the last group) showed great improvement comparable with that seen in auricular fibrillation. Slowing occurred once only in each group.

Mackenzie (1911) was not impressed with digitalis effect in failure with normal rhythm, though he recognized that digitalis might on occasion produce a satisfactory diuretic response and independently of the heart-rate. He laid great stress on the beneficial effect of rest in bed when the rhythm was normal, and attributed to it much of the apparent digitalis response.

Hay, Jones, and Ince (1927) gave digitalis tincture until toxic symptoms appeared in nine controlled cases of failure with normal rhythm. Four cases showed benefit, the greatest being seen in rheumatic valvular disease with œdema. They found that fall in heart-rate was not necessarily accompanied by subjective improvement. Kellum (1932) studied digitalis diuresis in twelve controlled patients with failure and œdema, with one exception normal rhythm being present. Diuresis was moderate in three and slight in four cases, but fluids were restricted to an average of 770 c.c. $(27 \mathrm{oz}$.) per day. The pulse was reduced in one-half the cases to an extent of an average of thirteen beats per minute. In an analysis of case records of failure with sinus mechanism, Hyman and Fenichel (1932) found that moderate doses of digitalis improved only 4 of 13 arteriosclerotic patients and none of 9 in the rheumatic group. Reduction in heart-rate itself was reckoned as evidence of improvement. In the presence of auricular fibrillation, digitalis helped 22 of 27 arteriosclerotic and all 30 rheumatic cases. Nineteen ambulatory patients with paroxysmal dyspnœa and normal rhythm were studied by Harrison, Calhoun, and Turley (1931). Sixteen cases were completely relieved by digitalis. As paroxysmal dyspnœa is a special product of left ventricular failure, we regard this result as of great practical importance. While investigating the effect of digitalis in over 100 cases of pulsus alternans in sinus rhythm, Windle (1917) opined that it could be given " with the confidence in a first attack of dropsy that it will almost surely do good." In an earlier paper dealing with rheumatic heart disease, Windle (1913) concluded that " digitalis often acts as well, as certainly, and as speedily on the general symptoms of heart disease with dropsy and regular pulse as it does in like cases of auricular fibrillation." In children under 14 with rheumatic infection and failure with normal rhythm, Sutherland (1919) concluded that the digitalis in rapid heart action was as specific in reducing the heart rate as in auricular fibrillation and that the beneficial effects were as striking. When the pulse-rate rose it could be repeatedly lowered by digitalis. 
The general conclusion of these investigators is that digitalis is indicated in heart failure with normal rhythm and that it often succeeds, though not so often and seldom so well as in heart failure with auricular fibrillation. Christian (1922) and Luten (1924) are exceptional in claiming that it succeeds as frequently and as well in normal rhythm as in auricular fibrillation. Opinions expressed by West and Pratt (1920), Robinson (1923), Fraser (1924), Robinson, White, Eggleston, and Hatcher (1924), Cushny (1925), Levy and Mackie (1927), Bramwell (1937), and East (1937) support the general conclusion, which is also the teaching found in current books on cardiology, e.g. Lewis (1937), White (1937), Fishberg (1937), East and Bain (1936), Levine (1936), Cowan and Ritchie (1935), and Harrison (1935).

In French reports the rhythm is not much considered in this relation, and Laubry (1938) says that digitalis is suitable for all cases of cardiac failure. Among German books, Scherf (1938) says that quite good digitalis action can be observed in hearts in failure without fibrillation because of the drug's action on the contractile power of the heart muscle, and that slowing of the heart-rate need not be produced. The most striking results occur in fibrillation, when the rate is rapid because slowing is produced. If the heart-rate is between 70 and 80 , the conditions are closer to those with normal rhythm.

\section{Results Obtained in this Series}

There were 47 patients, 36 males and 11 females, on whom 58 tests on digitalis effect were carried out. In the great majority (42 of 47) the failure was moderate or great on admission. The patients were divided into five groups and the group distribution is indicated in Table $\mathrm{I}$.

For purposes of comparison there were 30 cases of failure with auricular fibrillation on whom 32 tests were made. Again the majority (22 in 30) were in moderate or great failure on admission. As expected, the association being rare, there were no syphilitic cases with fibrillation. Unlike the normal rhythm series where each ætiological group (except Group 5) is well represented, almost half the fibrillating cases were rheumatic.

TABLE I

RESULTS OF DIGITALIS TREATMENT IN HEART FAILURE (1) WITH NORMAL RHYTHM, AND (2) WITH AURICULAR FIBRILLATION NORMAL RHYTHM

\begin{tabular}{c|c|c|c|c|c}
\hline GROUP & BASIS OF FAILURE & $\begin{array}{c}\text { NUMBER } \\
\text { OF } \\
\text { PATIENTS }\end{array}$ & $\begin{array}{c}\text { NUMBER } \\
\text { OF } \\
\text { TESTS }\end{array}$ & $\begin{array}{c}\text { CLINICAL } \\
\text { IMPROVEMENT } \\
\text { (IN TESTS) }\end{array}$ & $\begin{array}{c}\text { REDUCTION IN } \\
\text { RATE } \\
\text { (IN TESTS) }\end{array}$ \\
\hline 1. & $\begin{array}{l}\text { Hypertension } \\
\text { Hypertension and past } \\
\text { Coronary Thrombosis }\end{array}$ & 25 & 32 & 19 & 14 \\
3. & $\begin{array}{l}\text { Chronic Rheumatic Val- } \\
\text { vular Disease. } \\
\text { Syphilitic Heart Disease. } \\
\text { Unclassified. }\end{array}$ & 11 & 14 & 10 & 7 \\
4. & $\begin{array}{c}\text { Total . . } \\
5 .\end{array}$ & 47 & 58 & 5 & 6 \\
\hline
\end{tabular}


TABLE I-continued

Auricular Fibrillation

\begin{tabular}{|c|c|c|c|c|c|}
\hline GROUP & BASIS OF FAILURE & $\begin{array}{l}\text { NO. OF } \\
\text { PATIENTS }\end{array}$ & $\begin{array}{l}\text { NO. OF } \\
\text { TESTS }\end{array}$ & $\begin{array}{l}\text { CLINICAL } \\
\text { IMPROVEMENT } \\
\text { (IN TESTS) }\end{array}$ & $\begin{array}{l}\text { REDUCTION IN } \\
\text { RATE } \\
\text { (IN TESTS) }\end{array}$ \\
\hline 1. & $\begin{array}{l}\text { Hypertension } \\
\text { Hypertension and past }\end{array}$ & 12 & 14 & 9 & 10 \\
\hline 3. & $\begin{array}{l}\text { Coronary Thrombosis } \\
\text { Chronic Rheumatic Val- }\end{array}$ & 14 & 14 & 12 & 14 \\
\hline \multirow[t]{2}{*}{$\begin{array}{l}4 . \\
5 .\end{array}$} & $\begin{array}{l}\text { Syphilitic Heart Disease } \\
\text { Unclassified. }\end{array}$ & $\begin{array}{l}0 \\
4\end{array}$ & $\overline{4}$ & $\overline{2}$ & $\overline{4}$ \\
\hline & $\begin{array}{cc}\text { Total } & \ldots \\
\text { Percentage of Tests } & \ldots\end{array}$ & 30 & 32 & $\begin{array}{c}23 \\
71 \cdot 9 \%\end{array}$ & $\begin{array}{c}28 \\
87 \cdot 5 \%\end{array}$ \\
\hline
\end{tabular}

The good effect of rest in bed without other treatment is discussed later, the influence of this on the pulse-rate, weight, and balance of fluid intake and urinary output in one patient is shown here in Fig. 1.

Of the 58 tests on digitalis effect in normal rhythm, $35(60 \%)$ were successful, there being $17(29 \%)$ with slight benefit and $18(31 \%)$ with moderate or great benefit. Only $7(12 \%)$ showed striking improvement and a composite chart is given of four of them (Fig. 2). In this chart the dose is given as gr. ii, t.i.d. correctly for three of the cases, but the fourth had gr. iii, t.i.d. ; a similar

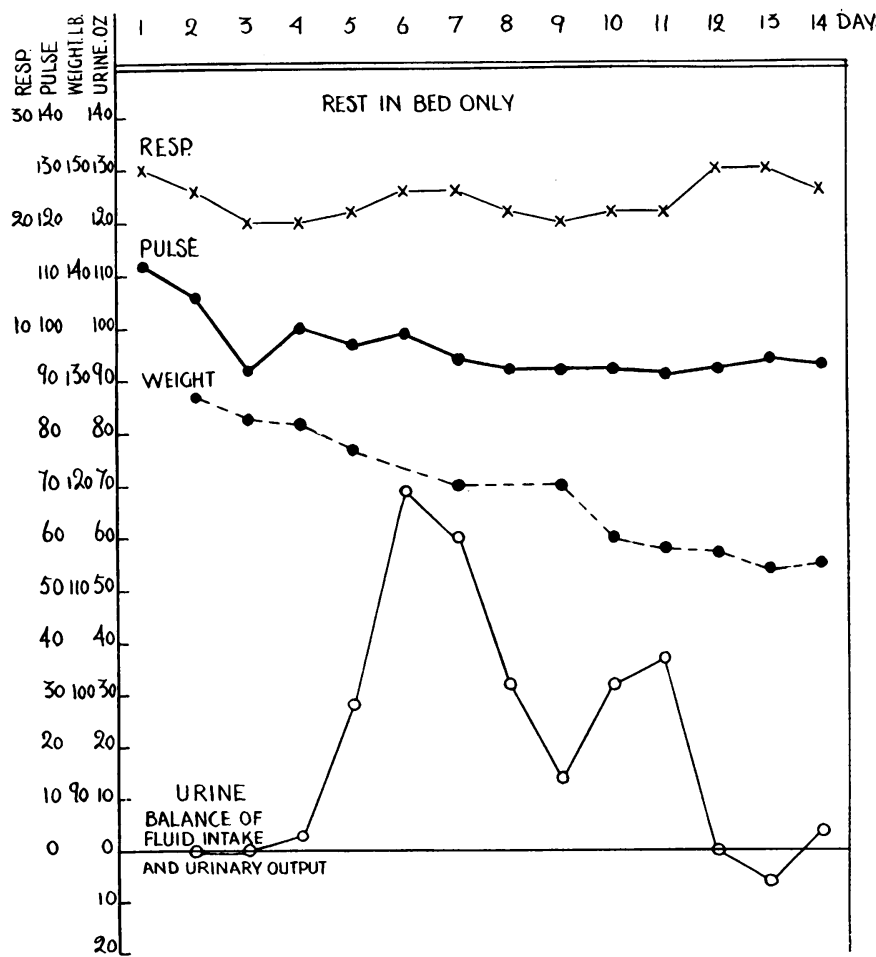

FIG. 1.-Effect of rest in bed alone in heart failure with normal rhythm. Woman, aged 52, with hypertensive heart disease, gross œdema, and hydrothorax. 


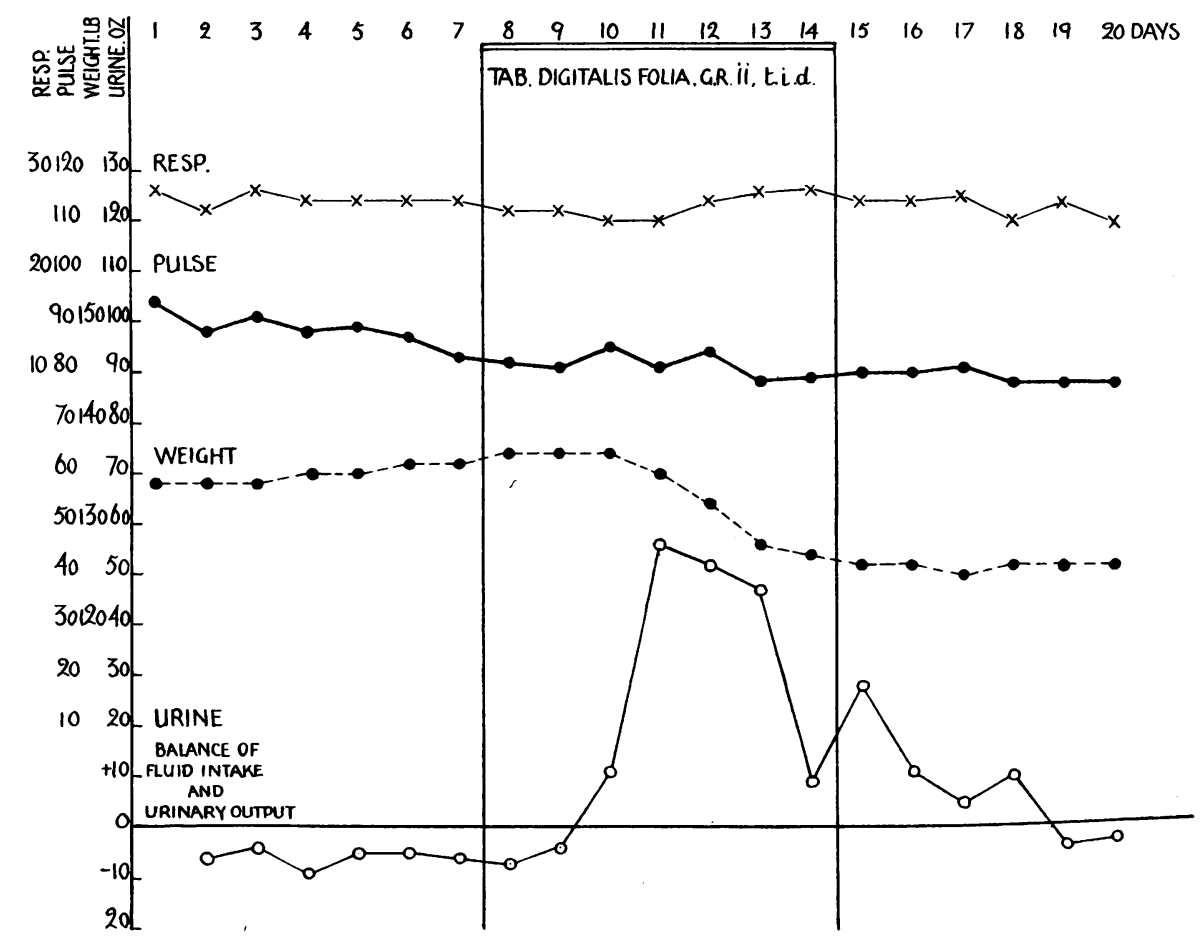

FIG. 3.-Absence of effect of digitalis in failure with normal rhythm, and the subsequent effect of a mercurial diuretic. A composite chart from four severe cases, all with œdema. 
exception holds for Fig. 3, which shows the complete ineffectiveness of digitalis in four cases. These results are rather disappointing, especially with regard to the infrequency of striking benefit, for only about one in eight patients in failure with normal rhythm can be expected to respond thus well. Nevertheless the majority benefit to some extent and would probably benefit more from administration over long periods.

In the series with auricular fibrillation, some degree of benefit from digitalis was seen more often, though not much oftener than in normal rhythm $(72 \%$ against $60 \%$ ). The incidence of great improvement was however more than twice that in normal rhythm $(28 \%$ against $12 \%)$.

Diuresis occurred in about half of all test courses in normal rhythm (27 in $58)$; it was moderate in eight and striking in six (10.3\%). The majority (24 of 35 ) of the observations with benefit were, as expected, accompanied by diuresis.

In auricular fibrillation diuresis occurred in 14 of 32 tests, much as in normal rhythm. Diuresis was moderate in eight and striking in four $(12.5 \%)$. Of 23 with benefit, 16 showed diuresis.

Successive Courses of Digitalis in the Same Individual.-When a patient in failure with normal rhythm benefits from digitalis on a first occasion, he is likely to respond again when in failure some weeks or months later : six of eight patients responded thus. If digitalis fails at the first test, it does not follow that it will fail again ; indeed, of four failing to respond at the first, two responded at a second test when again in failure.

\section{Factors Which may Influence Digitalis Response}

\section{(a) Rest in Bed.}

The effect of rest in bed during the control period was evaluated in the 47 cases with normal rhythm. Benefit occurred in 17 (about 40\%); in 9 it was moderate or great, and in 1 of these it was outstanding (Fig. 1). Nine patients, six of them with hypertension, became worse during the rest period. Of these nine, five were considerably improved by digitalis, in three the immediate downward trend of failure was arrested, while the remaining patient became worse on digitalis and died.

Mackenzie (1911) and Janeway (1913) having drawn attention to the effect of rest, most subsequent investigations on digitalis have been controlled in this way. But rest also remains a factor in enhancing digitalis effect during the course. If progress has not become stationary on rest alone, then the " rate of progress" (Luten, 1924) becomes important when assessing the benefit from digitalis.

Contrary to what was expected, benefit from rest in bed was only a little less frequent in the fibrillating cases. All the seven patients (four in the rheumatic group) who deteriorated on rest in bed benefited from digitalis. 
(b) The Nature of the Heart Disease.

No great difference was found in digitalis response between the various ætiological groups with normal rhythm, though the rheumatic group responded best. In fibrillation, however, the rheumatic group responded far better than any other (Table I). Excepting the rheumatic group, the separate ætiological groups with fibrillation showed little better results than the corresponding groups with normal rhythm.

\section{(c) The Heart-rate.}

The heart-rate is not usually very frequent in failure with normal rhythm. In 47 patients on admission, the average was 91 , and at the end of the control rest period it had fallen to 86 . In the rheumatic group (which showed most improvement) the average rate was only 82 . Table II shows that digitalis reduced the heart-rate in about half of the 58 tests $(46 \%)$. Benefit resulted in two-thirds (18 of 27) of those with and in about half (17 of 31) of those without slowing. Considerable slowing (over 15) was rather more often accompanied by clinical improvement than was slight slowing (below 15) ; and in each of five cases with a great reduction in rate (over 30), benefit always occurred. Slowing, especially if great, is therefore a promising sign though it is not necessarily followed by clinical improvement; and improvement is by no means dependent on slowing, as Figs. 2 and 3 indicate.

TABLE II

THE EFFECT OF DIGITALIS ON THE HEART-RATE IN HEART FAILURE

(1) WITH NORMAL RHYTHM, (2) WITH AURICULAR FIBRILLATION

\begin{tabular}{|c|c|c|c|c|c|c|}
\hline & & & & \multirow{2}{*}{$\begin{array}{l}\text { NORMAL } \\
\text { RHYTHM }\end{array}$} & \multicolumn{2}{|c|}{ AURICULAR FIBRILLATION } \\
\hline & & & & & NON-RHEUMATIC & RHEUMATIC \\
\hline $\begin{array}{l}\text { No. of cases .. . } \\
\text { No. of observations. } \\
\text { (a) With reduction in rate } \\
\text { Rate before digitalis } \\
\text { Rate after digitalis } \\
\text { Average fall in rate } \\
\text { Benefit from digitalis } \\
\text { No benefit from digital } \\
\text { (b) Without reduction in ra } \\
\text { Rate before digitalis } \\
\text { Benefit from digitalis }\end{array}$ & $\begin{array}{c}\ldots \\
\cdots \\
\cdots \\
\ldots \\
\ldots \\
\cdots \\
\cdots \\
\text { lis } \\
\text { ate }\end{array}$ & $\begin{array}{l}\cdots \\
\cdots \\
\cdots \\
\cdots \\
\cdots \\
\cdots \\
\cdots \\
\cdots \\
\cdots \\
\cdots\end{array}$ & $\begin{array}{l}\cdots \\
\cdots \\
\cdots \\
\ldots \\
\cdots \\
\cdots \\
\cdots \\
\cdots \\
\cdots \\
\cdots\end{array}$ & $\begin{array}{c}47 \\
58 \\
27 \\
(46 \%) \\
85 \\
67 \\
18 \\
18 \\
(67 \%) \\
9 \\
(33 \%) \\
31 \\
(54 \%) \\
85 \\
17 \\
(55 \%)\end{array}$ & $\begin{array}{c}16 \\
18 \\
14 \\
(78 \%) \\
93 \\
70 \\
23 \\
9 \\
(64 \%) \\
5 \\
(36 \%) \\
4 \\
(22 \%) \\
89 \\
0\end{array}$ & $\begin{array}{c}14 \\
14 \\
14 \\
(100 \%) \\
108 \\
70 \\
38 \\
12 \\
(86 \%) \\
2 \\
(14 \%) \\
0 \\
- \\
-\end{array}$ \\
\hline
\end{tabular}

Some authors (Lewis, 1919 ; Sutherland, 1919 ; Eggleston, 1920 ; Cushny, 1925 ; Levy and Mackie, 1927 ; and Fishberg, 1937) have held that digitalis 
is more likely to induce slowing if there is tachycardia. We agree in part, for four of the five cases above mentioned with a striking reduction in rate had a high initial rate (over 90). But, in general, slowing was as common when the initial rate was near the normal as when it was higher.

No relation between the ætiology of failure in normal rhythm and slowing from digitalis was discovered; and slowing in the rheumatic group was not more often seen than in the other groups (Table I). Extensive myocardial damage need not prevent a fall in rate, for the group of hypertension with past coronary thrombosis showed the same incidence of slowing as the other groups. In three of seven cases with bundle branch block, digitalis reduced the rate.

Unlike Cohn (1915) and Eggleston (1920), we found that slowing, whether slight or great, was more common in the absence than in the presence of œdema (70 per cent. against 40 per cent.). Yet slowing was common enough among the œdematous. Digitalis diuresis had no relation to the fall in rate, nor had the severity of failure.

The Rate Factor in Failure with Auricular Fibrillation.-The average rate on admission for all cases, again in Groups 1 to 5 , was 111,20 points higher than the corresponding figure in normal rhythm. Rest alone produced an average fall of 10. Digitalis caused a reduction in rate in 28 of 32 observations $(87.5 \%)$, and of these 75 per cent. showed benefit. The average fall was 30 . Of the remaining four cases which showed no slowing, none were improved. The rate factor was evidently more important in auricular fibrillation than in normal rhythm ; for the initial rate was higher, slowing by digitalis was much commoner and in its absence no benefit accrued.

Looking at the ætiological groups, rheumatic valvular disease stood out in many respects : the rate on admission was 121 (148 if no digitalis had been given before admission); rest induced a fall of 13 ; digitalis invariably reduced the rate with an average fall of 38 ; and 86 per cent. derived benefit. Considering the rate factor within the rheumatic fibrillation group, it was the patient with a rapid ventricular rate of over 100 who responded best to digitalis (Fig. 4). Even if we took those with a rate below 100 , the response to digitalis was distinctly better than in non-rheumatic fibrillation, i.e. 72 per cent. against 50 per cent. But it was no better than in rheumatic cases with normal rhythm and a comparable rate of 81 and 82 , i.e. 72 per cent. in each. Digitalis may act well in older patients (over the age of 60 ) in failure and fibrillation with an infrequent rate (under 80), a group to which some attention has been given by Mackenzie (1911) and Fraser (1928) ; we had five such cases, two of whom not only improved greatly, but showed the greatest reduction in rate-16 and 20 .

Table II analyses the rate factor. The non-rheumatic cases of fibrillation occupy an intermediate position between those with normal rhythm and the rheumatic cases with fibrillation. Despite the greater slowing, non-rheumatic fibrillation was no more helped by digitalis than was normal rhythm. The rheumatic group with fibrillation alone justifies the prominence given to the rate factor in digitalis response in failure. This, too, is the group where digitalis can exert its well-known power of controlling the rate and so of prevent- 
ing the recurrence of failure. No one claims that digitalis has the same value either in controlling rate or in warding off failure when the rhythm is normal ; though it should, of course, be used with these objects in view.

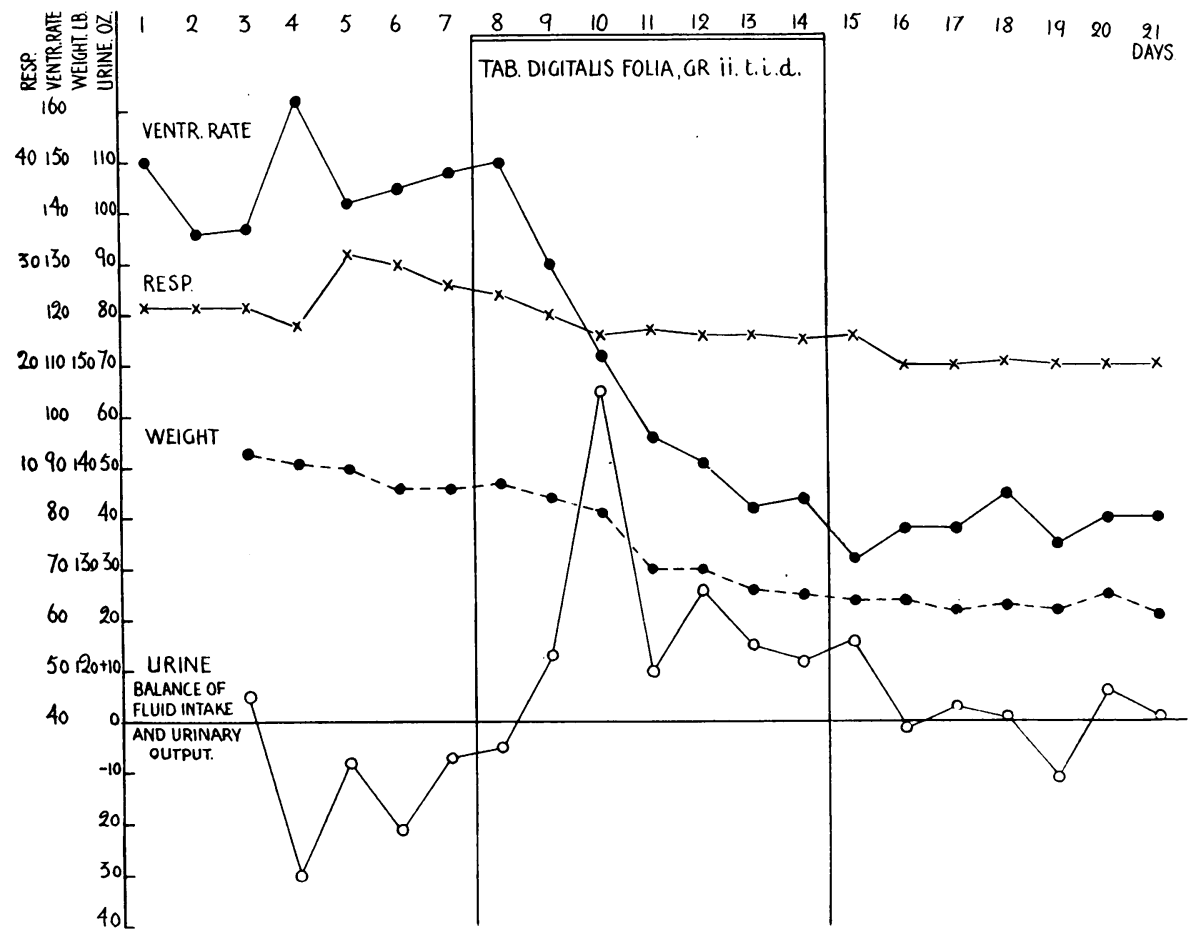

FIG. 4.-Effect of digitalis in rheumatic heart failure with auricular fibrillation. Woman aged 64 with mitral stenosis, great œdema, and hydrothorax

\section{(d) Edema.}

We included cases without demonstrable œdema at the end of a control period (most had œdema on admission), provided there remainded ample evidence of failure ; and digitalis was by no means without effect upon them. In fact, considerable benefit was obtained as often without as with œdema, and some response occurred in 75 per cent. without œdema against 52 per cent. with œdema. Figures for the fibrillation series ran parallel.

Though with normal rhythm considerable diuresis was twice as common in patients with œdema, yet some diuresis was not uncommon without œdema, 6 in 16. Thus we cannot go so far as some (Hay, Jones, and Ince, 1927) who have stated that no œdema means no diuresis. In patients with cardiac failure, several pints of fluid may be retained in the tissues before œdema becomes manifest, and a digitalis diuresis reveals what has really been latent.

In the auricular fibrillation series without œdema, considerable diuresis was even more common than in normal rhythm without œdema (6 in 12 against 2 in 16). 
(e) Hydrothorax. Respiratory Rate.

There were 13 normal rhythm cases with hydrothorax; in six it was on the right, in four on the left, and in three bilateral. The rheumatic group was not represented ; syphilitic heart disease accounted for three (one right, two left) ; and the remainder were in the two hypertension groups. Digitalis dispelled the hydrothorax in five and reduced it in one. Though the hydrothorax was not appreciably affected in three patients, they derived benefit from the drug in other directions, e.g. loss of œdema. Patients with hydrothorax responded like those without.

It was remarked that even with hydrothorax the charted rate of respiration immediately before digitalis was in some cases as low as 20 , the average being 25 , as it was also in severe failure without hydrothorax. With improvement on digitalis the respiratory rate usually fell, though the average fall was only two or three; sometimes there was no fall (Fig. 2).

In five cases of auricular fibrillation with right hydrothorax, digitalis was effective, the hydrothorax being dispelled completely in two and reduced in one.

Thus in severe failure, whatever the rhythm, digitalis is as likely to benefit a patient with a hydrothorax as one without.

\section{( $f$ ) The Duration of Incapacity.}

It might have been thought that in cases with normal rhythm and failure of short standing (under 6 months), the immediate results from digitalis would be better than in those of longer standing, but this idea was not supported by our figures, any more than the idea that patients in a first failure would respond better than in a subsequent failure. The same observations apply to auricular fibrillation.

\section{(g) The Severity of Failure.}

This did not much matter in deciding whether digitalis would act or not. Fourteen of 20 tests in slight failure and 17 of 38 in moderate or great failure were successful. In fibrillation the proportions were 8 of 12 in slight failure, and 15 of 20 in moderate or great failure.

The superiority of digitalis in auricular fibrillation is most evident if the severer grades of failure are alone considered. Only 7 of 38 in normal rhythm responded brilliantly, but no fewer than 9 of 20 in auricular fibrillation.

\section{(h) Age and Prognosis.}

The age factor arises chiefly in relation to ætiology. The rheumatic cases with normal rhythm were on an average 22 years younger and the syphilitic group on an average 8 years younger than the hypertension groups, where the average age was 61 . The age factor proved to be of little importance, though the tendency was for a decline in digitalis response as age advanced. Yet among those aged 65 to 70 , no fewer than five of nine patients responded and two of them well. 
The pathological basis of failure could not be correlated with the likelihood of digitalis response. In auricular fibrillation, however, the incidence of benefit was far greater in the rheumatic group than in the non-rheumatic groups, and this has been discussed above, under ' $c$ '.

We thought it likely that in patients with normal rhythm, whose survivalperiod proved to be under one year, digitalis might be less effective. This did not prove to be the fact, for of 18 patients who died within a year, 10 had benefited from digitalis and 8 had not. Moreover, of four who died within a few weeks of uncomplicated heart failure (proved at necropsy in three), two responded well to digitalis, a proportion not very different from those with a better prognosis. There was no essential difference in the death rate between the ætiological groups in normal rhythm, and we know that 18 of 29 patients who were followed up to July 1938 died within a year.

Comparison of Digitalis Effect during Normal Rhythm and during Auricular Fibrillation in the Same Individual.-There were five such cases, in two of which the fibrillation was produced or more likely precipitated by digitalis. It happened that the average rate was the same in normal rhythm as in auricular fibrillation, i.e. 88. Under digitalis during normal rhythm, the rate fell to 81 , while during auricular fibrillation the rate fell to 66 : a fall of 7 and 22 respectively. As to clinical benefit, we have adequate observations on four of them, and in two digitalis failed both in normal rhythm and in auricular fibrillation. In the other two digitalis gave a better clinical result when fibrillation obtained.

\section{Digitalis and Mercurial Diuretics}

When a course of digitalis failed, a mercurial diuretic was often given. In 16 such cases with normal rhythm it invariably produced a diuresis; it never failed even where œdema was absent, though naturally the greatest response was in the œdematous. The previous administration of digitalis appeared to make no difference to the diuretic response, and this confirms the experience of Thomson (1937). Fig. 3 shows the good effect of a mercurial diuretic in four patients who had not been helped by digitalis.

Salyrgan is more than an adjuvant in failure with œdema, but it does not meet the inherent difficulty-myocardial insufficiency. At the best a mercurial diuretic simply removes collected and stagnant fluid and thereby relieves the patient. Digitalis acts often enough under observation, as we have shown, to make it likely that more prolonged use in adequate doses will extend improvement and postpone relapse.

\section{Subsidiary Groups (6-10)}

These groups comprising 18 patients (22 tests) with normal rhythm are separately considered for reasons obvious in the diagnosis.

Group 6. Congenital Heart Disease ; three cases, three tests.

Two patients, aged 63 and 11, had Fallot's tetralogy. Both responded slightly to digitalis. The remaining patient, aged 43 , with coarctation of the aorta, was not improved. 
Group 7. Rheumatic Carditis with Valvular Disease; seven cases, nine tests.

The average age was only 17. All had considerable œdema. A single patient improved on digitalis and two others showed a reduction in rate from an average of 125 to 97 . Six died later, four within a few months and two within two years.

Group 8. Infective Endocarditis; three cases, four tests.

Post-mortem proof of the diagnosis was obtained in all three cases. In a single patient digitalis increased the urinary output with slight temporary benefit, but no effect at all was demonstrable in the others.

Group 9. Complete Heart-block; two cases, two tests.

Both patients had slight œdema. One improved with a diuresis and a slight fall in ventricular rate from 32 to 27 ; the other was unaffected.

Group 10. Chronic Nephritis; three cases, four tests.

All had cardiac failure. In the one patient without œdema, digitalis relieved the dyspnœa and abolished Cheyne-Stokes respiration and pulsus alternans. The other two patients, with œdema, improved and showed diuresis.

\section{Summary AND CoNClusions}

1. This investigation was undertaken primarily to decide the clinical value of digitalis in heart failure with normal (sinus) rhythm. The secondary purpose was to compare its value in such failure with that in auricular fibrillation, which is better known.

2. Sixty-five patients with heart failure and normal rhythm were observed. After one week or more at rest in bed, digitalis leaf was given in a dose of 2 grains three times a day, i.e. 6 grains $(0.4 \mathrm{~g}$.) daily, for one to two weeks. The condition at the beginning of digitalis treatment was compared with that at the end. The criteria of failure were dyspnœa, liver enlargement, and œdema with or without hydrothorax ; and judgment as to improvement was made on these criteria together with diuresis. Reduced heart-rate was not reckoned as a criterion, and it is separately considered. Twenty-five patients had hypertensive heart disease, 12 with and 13 without past coronary thrombosis ; 11 had chronic rheumatic valvular disease ; 9 had syphilitic heart disease; and 2 were unclassified. In these, the main groups, the majority, 72 per cent., had œdema at the end of the week's rest in bed and a quarter of these had hydrothorax, confirmed by X-ray examination.

3. The control lay in the preliminary rest in bed without digitalis ; but for comparison another series of 30 patients with failure and auricular fibrillation was observed in the same way.

4. Under rest in bed only, in normal rhythm, 17 of $47(36 \%)$ improved ; in auricular fibrillation, 11 of $28(39 \%)$ improved.

5. The main digitalis results are shown in Table $I$ and there are illustrative charts of effect and of failure of effect. In normal rhythm some clinical improve- 
ment was demonstrated in 35 out of 58 tests $(60 \%)$; and 23 of 58 showed none. Admittedly 17 received only slight benefit, so that moderate or great benefit resulted in 18 only, i.e. 31 per cent. of the whole. There was little difference in response among the separate ætiological groups, though the rheumatic group responded best (Table I).

The heart-rate in failure with normal rhythm is moderate, the average in our series before digitalis being 85 . It was reduced by digitalis in 27 out of the 58 tests (47 patients), i.e. in almost half $(46.5 \%)$. The average fall in rate among those in whom it occurred was from 85 to 67 , i.e. 18 . This was usually secured without toxic symptoms, and when these appeared $(20 \%)$ they were slight (nausea and rarely vomiting). Whatever the initial rate, digitalis often reduced it. Reduction in rate was not always accompanied by clinical improvement, though improvement was rather more common in the patient who showed it. Some good clinical results were seen without any reduction in rate (Table II).

Diuresis was induced by digitalis in 27 of 58 tests (47 patients) in normal rhythm. It was freer in patients with gross œdema than in those with little or none ; but some diuresis was obtained almost as frequently in those without as in those with œdema.

The course of the disease after the onset of failure in normal rhythm is short-18 of 29 patients died within a year-and this in general must lessen the likelihood of improvement from digitalis. Yet in a particular patient the response to digitalis is no guide to the expectation of life ; and if digitalis fails at a first trial, it may occasionally succeed at a later trial.

6. Of the patients with auricular fibrillation, 12 had hypertensive heart disease, 14 had chronic rheumatic valvular disease, and 4 were unclassified. Clinical improvement was demonstrated in 23 of 32 tests (30 patients), i.e. in 72 per cent. ; and 9 showed none. It was slight in nine, and moderate or great in fourteen, i.e. 44 per cent. of the whole.

The heart-rate was higher than in the normal rhythm series, an average of 98 against 85 , a difference of 13 . The rate was reduced by digitalis in the great majority, in 28 of 32 tests $(87 \%)$. The average fall in rate where a fall resulted was from 100 to 70 , an average fall of 30 . Most of those with slowing also showed benefit, but in the absence of slowing there was none.

The rheumatic group was distinguished by a higher average rate before treatment, by reduction of the rate in all fourteen cases, and by clinical improvement in all but two. Even with a moderate initial rate (below 100), results were better in rheumatic than in non-rheumatic fibrillation, though no better than in rheumatic cases with normal rhythm.

Without the rheumatic group, the fibrillation series responded to digitalis no better than the normal rhythm series. In hypertension, for instance, the results were similar.

7. A mercurial diuretic sometimes administered after a digitalis test nearly always produced a free diuresis even where digitalis had failed. In œdematous patients other than those with rheumatic auricular fibrillation and a high ventricular rate, a mercurial diuretic usually has more value than digitalis. Yet a trial of digitalis cannot be omitted, for it alone acts directly on the heart. 
The partnership of a mercurial diuretic with digitalis should govern the treatment of heart failure.

8. Digitalis is always indicated in congestive heart failure irrespective of rhythm, but it is often inefficient, as it fails completely in about a third of all cases.

In heart failure with normal rhythm digitalis is helpful in rather more than half the cases.

In heart failure with auricular fibrillation, digitalis is more often helpful than it is in normal rhythm, for it benefits more than two-thirds. This superiority rests on its particular value in rheumatic heart failure with fibrillation, largely but not entirely due to the high ventricular rate. Incidentally, it is in this group that rate control by continued digitalis best prevents recurrence of the failure.

The real difference in the response of heart failure to digitalis lies not between auricular fibrillation and normal rhythm, but rather between rheumatic auricular fibrillation and all other kinds of heart failure irrespective of rhythm.

We are indebted to Drs. C. Hollins, R. W. Parnell, and F. S. Cosh, house physicians to the Cardiac Department, for their great assistance in recording clinical observations ; and to the Sisters of the Wards for their valued co-operation. Dr. John Grimshaw has kindly advised us on the text.

\section{REFERENCES}

Bramwell, C. (1937). Brit. Ency. Med. Pract., 6, 381.

Christian, H. A. (1919). Amer. J. med. Sci., 157, 593. - (1922). Med. Clin. N. Amer., 5, 1,173.

Cohn, A. E. (1915). J. Amer. med. Assoc., 65, 1,527.

Cowan, J., and Ritchie, W. T. (1935). Diseases of the Heart, 3rd edit., London.

Cushny, A. R. (1925). The Action and Uses in Medicine of Digitalis and its Allies, London.

East, T. (1937). Failure of the Heart and Circulation, London.

- and Bain, C. (1936). Recent Advances in Cardiology, 3rd edit., London.

Eggleston, C. (1920). Amer. J. med. Sci., 160, 625

Fishberg, A.M. (1937). Heart Failure, London.

Fraser, F. R. (1924). St. Bart.'s Hosp. Rep., 57, 22.

- (1928). Med. J. Australia, 2, 550.

Harrison, T. R. (1935). Failure of the Circulation, Baltimore.

- Calhoun, J. A., and Turley, F. C. (1931), Arch. intern. Med., 48, 1,203.

Hay, J., Jones, H. W., and Ince, P. (1927). Quart. J. Med., 21, 153.

Hyman, H. T., and Fenichel, N. M. (1932). Amer. J. med. Sci., 183, 748.

Janeway, T. C. (1913). Trans. 17th Internat. Congress Medicine, London, Sect. V Therapeutics.

Kellum, E. L. (1932). Amer. Heart J., 7, 342.

Laubry, C. (1938). Leçons de Cardiologie, Paris.

Levine, S. A. (1936). Clinical Heart Disease, Philadelphia and London.

Levy, R. L., and Mackie, T. T. (1927). J. Amer. med. Assoc., 89, 432.

Lewis, T. (1919). Brit. med. J., 2, 621.

- (1937). Diseases of the Heart, 2nd edit., London.

Luten, D. (1924). Arch. intern. Med., 33, 251.

- (1936a). Amer. Heart J., 12, 435.

- - (1936b). The Clinical Use of Digitalis, Illinois.

Mackenzie, J. (1911). Heart, 2, 273.

Marvin, H. M. (1927). J. Clin. Invest., 3, 521.

Parkinson, J., and Clark-Kennedy, A. E. (1926). Quart. J. Med., 19, 113.

Robinson, G. C. (1923). The Therapeutic Use of Digitalis, Baltimore. 
Robinson, G. C., White, P. D., Eggleston, C., and Hatcher, R. A. (1924). J. Amer. med. Assoc., 83, 504.

Scherf, D. (1938). Klinik und Therapie der Herzkrankheiten und der Gefässerkrankungen, 4th edit., Vienna.

Sutherland, G. A. (1919). Quart. J. Med., 12, 183.

Thomson, W. A. R. (1937). Quart. J. Med., 30, N.S.6, 321.

West, H. F., and Pratt, J. H. (1920). J. Amer. Med. Assoc., 75, 77.

White, P. D. (1937). Heart Disease, 2nd edit., New York.

Windle, J. D. (1913). Trans. 17th Internat. Congress Medicine, London, Sect. V Therapeutics. (1917). Quart. J. Med., 10, 274. 